\title{
Demonstrating a low temperature organic dense dielectric patch antenna
}

\author{
R J Espley-Jones ${ }^{\dagger} *$, K F Tong ${ }^{\dagger}$, J E J Dalley* ${ }^{*}$ J D S Langley*, \\ ${ }^{\star}$ Leonardo MW Ltd,300 Capability Green, Luton, LU1 3PG, UK \\ ${ }^{\dagger}$ Department of Electronic and Electrical Engineering University College London Torrington Place, London WCIE 7JE, UK
}

Keywords: Ethanol, liquid antenna, dense dielectric patch antenna.

\begin{abstract}
This paper demonstrates the possible implementation of a low temperature organic dense dielectric patch antenna (DDPA). Instead of using deionised water for the patch material, a mixture of ethanol and methanol was the material of choice as it remains liquid below $0^{\circ} \mathrm{C}$. The freezing points of ethanol and methanol are $-114.1^{\circ} \mathrm{C}$ and $-97.6^{\circ} \mathrm{C}$ respectively. The mixture was $80 \%$ ethanol, $20 \%$ methanol. Good return loss, efficiencies and gains are achieved. The maximum gain over the band of interest is $5.62 \mathrm{~dB}$ at $1.31 \mathrm{GHz}$.
\end{abstract}

\section{Introduction}

There exist a large variety of liquid materials such as eutectic gallium indium (EGaIn) [1], Galinstan (GaInSn), mercury $[2,3]$ and water[4,5] that have been shown to operate as antennas. These materials allow for novel research avenues, for example Galinstan has been shown not to wet its container allowing for a reconfigurable system to be achieved [6]. Both EGaIn and mercury are liquid below $0 \mathrm{C}^{\circ}$ allowing for larger temperature ranges of antennas [2]. Recently, water has become an increasingly large area of research due to its low cost, easy access and safety, as demonstrated by Li and Luk [7]. Whilst water antennas show promise in certain applications, they are limited by the temperature range of its liquid state. Losing this liquid state significantly hampers their reconfigurable nature.

Although an ionised liquid can lower the freezing point, it can in certain systems, such as a DDPA, severely degrade the antenna performance [7,8]. Therefore, an alternative liquid used for the radiator is required. Such a liquid would need a high permittivity and very low conductivity to ensure that the antenna functions as desired [8]. Alcohols, such as ethanol and methanol satisfy these requirements as well as being cheap, organic and easily accessible. Moreover, they exist in a liquid state far below $0 \mathrm{C}^{\circ}$ thus allowing for low temperature reconfigurability.

\section{Experimental Set Up}

Previous simulations and experiments have been conducted to verify that the DDPA system is suitable for this ethanol/methanol mixture. As a result, the DDPA geometry is similar to that reported by $\mathrm{Li}$ and Luk [8]. By changing the radiating material within the patch, the L-probe was optimised to a higher frequency as the ethanol/methanol mixture has a relative permittivity value of 30 . The geometry used in both the simulations and the measurements is shown in Figure 1.

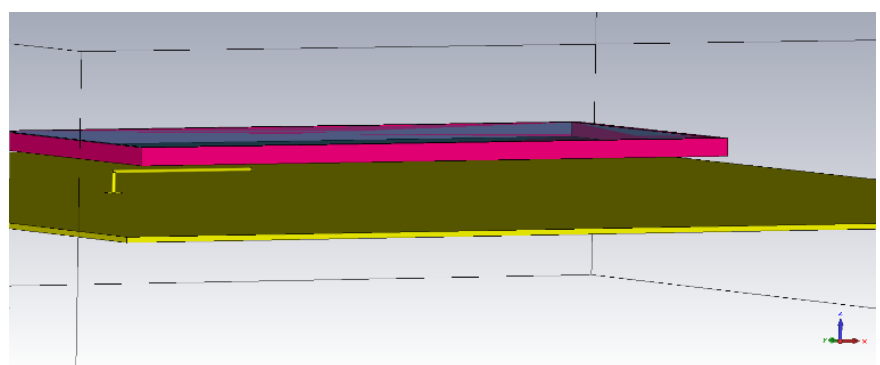

Figure 1. Geometry of ethanol/methanol mixture DDPA system highlighting the L-probe, patch (light blue) and 3D printed tray (pink).

The container for the ethanol/methanol mixture was 3D printed using stereo lithography-based technology. The material was polydimethylsiloxane (PDMS) which has a dielectric constant of 2.3 and a loss tangent of 0.05 [9].The system is driven by an L-probe feed through a SMA connector. The thickness of the liquid mixture was $5 \mathrm{~mm}$ and was located $10 \mathrm{~mm}$ above the copper ground plane.

Return Loss $\left(\mathrm{S}_{11}\right)$ measurements were taken using a Rohde \& Schwarz FSH8 PNA and compared against simulated results from both CST Microwave Studio and FEKO. In addition, measurements of gain were taken and efficiencies calculated.

\section{Results and Discussion}

The EM simulation tools were used to verify the geometrical set up. By taking into account the shorter L-probe used as a result of the change in permittivity, the system is centred on an operating frequency of $1.36 \mathrm{GHz}$. Table 1 highlights the system's characteristics when the ethanol/methanol mixture was used. Figure 2 shows $S_{11}$ obtained from the EM simulations.

\begin{tabular}{|l|l|l|l|}
\hline $\begin{array}{l}\text { Modelling } \\
\text { Tool }\end{array}$ & $\begin{array}{l}\text { Peak Gain } \\
(\mathrm{dB})\end{array}$ & $\mathrm{S}_{11}$ & $\begin{array}{l}\text { Efficiency } \\
(\%)\end{array}$ \\
\hline FEKO & 7.51 & -7.47 & 58.1 \\
\hline CST & 7.29 & -6.97 & 56.4 \\
\hline
\end{tabular}

Table 1. Results from FEKO and CST simulations showing, the peak realised gain, return loss and efficiency at $1.36 \mathrm{GHz}$. 


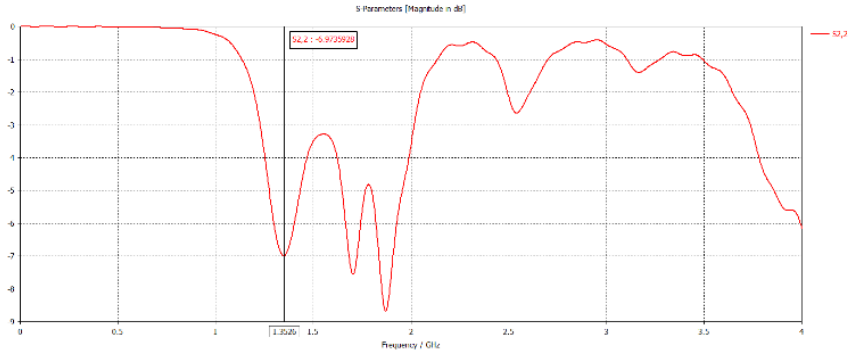

Figure 2. $\mathrm{S}_{11}$ of the DDPA system in CST.

The measured results for the same set up are shown in Table 2 and the resonant frequency of the patch is $50 \mathrm{MHz}$ lower than the simulated case.

\begin{tabular}{|l|l|l|l|}
\hline & $\begin{array}{l}\text { Peak Gain } \\
(\mathrm{dB})\end{array}$ & $\mathrm{S}_{11}$ & $\begin{array}{l}\text { Efficiency } \\
(\%)\end{array}$ \\
\hline $\begin{array}{l}\text { Physical } \\
\text { Model }\end{array}$ & 5.62 & -10.68 & 45.2 \\
\hline
\end{tabular}

Table 2. Results from measurements showing the peak gain, return loss and efficiency at $1.31 \mathrm{GHz}$.

In all three cases, (two simulated and one measured), the patch exhibits good gain despite the non-optimised match of the system. Ensuring that the L-probe or similar feed network is optimised to the introduction of the ethanol/methanol mixture will allow for higher efficiencies to be observed.

Nevertheless, a low temperature organic DDPA is achievable with the proposed design. The advantage of an alcohol mixture is that it introduces the possibility of the addition of de ionised water to further modify the permittivity of the system, thus change the centre frequency of operation. The ethanol/methanol mixture has been chosen to remain in its liquid state below $0^{\circ} \mathrm{C}$, but will not be suitable for temperatures above $70^{\circ} \mathrm{C}$.

\section{Conclusion}

A low temperature organic dense dielectric patch antenna (DDPA) has been proposed. Unlike other water-based or organic based systems, this antenna has a potential temperature range down to $-98^{\circ} \mathrm{C}$ allowing for use in very cold environments. The overall temperature bandwidth of the radiating liquid is larger than previously reported materials. A measured gain of $5.62 \mathrm{~dB}$ was obtained along with a peak efficiency of $45 \%$. This compares to $60 \%$ demonstrated by $\mathrm{Li}$ and Luk [8].

\section{Acknowledgements}

I wish to thank my colleagues at Leonardo MW Ltd., Mr Clark and Mr Robinson for their funding and support with this work.

\section{References}

[1] G. J. Hayes, J.-H. So, A. Qusba, M. D. Dickey, and G. Lazzi, "Flexible liquid metal alloy (EGaIn) microstrip patch antenna," IEEE Trans. Antennas Propag., vol. AP-60, no. 5, pp. 2151-2156, May 2012.

[2] Y. Kosta and S. Kosta, "Liquid antenna systems," in Proc. IEEE AP-S Int. Symp., Jun. 2004, pp. 2392-2395.

[3] Y. Kosta and S. Kosta, "Realization of a microstripaperture-coupledpassive-liquid patch antenna,' in Proc. IEEE Int. RF Microw. Conf., Dec. 2008, pp. 135-138

[4] S. S. Alja'afreh, Y. Huang, and L. Xing, "A compact dual-feed waterbased diversity antenna," in Proc. Loughborough Antennas Propag. Conf., Nov. 2013, pp. $182-185$.

[5] H. Fayad and P. Record, "Broadband liquid antenna," Electron. Lett., vol. 42, no. 3, pp. 133-134, Feb. 2006.

[6] M. D. Dickey, R. C. Chiechi, R. J. Larsen, E. A. Weiss, D. A. Weitz, G. M. Whitesides, "Eutectic galliumindium (EGaIn): A liquid metal alloy for the formation of stable structures in microchannels at room temperature", Adv. Functional Mater., vol. 18, pp. 10971104, 2008.

[7] H. W. Lai, K.-M. Luk, and K. W. Leung, "Dense dielectric patch antenna- A new kind of low-profile antenna element for wireless communications,' IEEE Trans. Antennas Propag., vol. 61, no. 8, pp. 4239-4245, Aug. 2013.

[8] Y. Li and K.-M. Luk, "A water dense dielectric patch antenna," IEEE Access, vol. 3, pp. 274-280, 2015.

[9] K. F. Tong, C. B. Fortuny, and J. Bai, "Low cost 3Dprinted monopole fluid antenna," in 2015 International Symposium on Antennas and Propagation (ISAP), 2015, pp. 1-4. 